\title{
Oxytocin trajectories and social engagement in extremely premature infants during NICU hospitalization
}

\author{
Ashley Weber ${ }^{\mathrm{a}}$, Tondi M. Harrison ${ }^{\mathrm{b}}$, Deborah Steward ${ }^{\mathrm{b}}$, Loraine Sinnott ${ }^{\mathrm{b}}$, and Abigail \\ Shoben ${ }^{\mathrm{C}}$ \\ ${ }^{a}$ Case Western Reserve University, N0B040 Frances Payne Bolton School of Nursing, 2120 \\ Cornell Road, Cleveland, OH 44106, USA \\ ${ }^{b}$ The Ohio State University College of Nursing, Newton Hall, 1585 Neil Avenue, Columbus, $\mathrm{OH}$ \\ 43210, USA \\ 'The Ohio State University College of Public Health, Cunz Hall, 1841 Neil Avenue, Columbus, $\mathrm{OH}$ \\ 43210, USA
}

\begin{abstract}
Extremely premature infants, born 28 weeks gestation or less, are at high risk for impaired socioemotional development, due in part to exposure to early stressful social experiences that alter brain development. Understanding mediators that link experience with outcomes is necessary to assess premature infant responses to social experiences that are critical to brain development. The hormone oxytocin (OT), released during supportive interactions, has potential as a biomarker of the premature infant's responses to social experiences. The purpose of this study was to examine associations among infant plasma OT trajectories and maternal-infant social engagement behaviors during initial hospitalization. This study also examined demographic correlates of engagement behaviors in mothers and infants. Plasma from 28 extremely premature infants, born gestational ages 25-28 6/7 weeks, was collected at 14 days of life, then weekly until 34 weeks. Social engagement behaviors were measured by the Parent-Child Early Relational Assessment during a videotaped feeding when the infant was receiving one-quarter full oral feeds. Maternal-infant demographics were extracted from the medical record. Higher infant plasma OT was associated with lower infant social engagement, but no associations were found with maternal social engagement. Infant social engagement was positively related to maternal social engagement. Maternal parity was related to maternal social engagement, and infant demographics did not predict infant social engagement. The significant, yet negative, association between infant OT and engagement provides support for the measurement of OT as a neurobiological antecedent to infant social behaviors. Finally, this research suggests that during the earliest period of infant sociobehavioral development, premature infants are behaviorally reactive to the social engagement behaviors of their mothers.
\end{abstract}

Correspondence to: Ashley Weber.

Conflicts of interest

The authors declare no conflicts of interest. 


\section{Keywords}

Oxytocin; Premature infant; Neurodevelopment; Social engagement; Development

\section{Introduction}

For all infants, the quality of early life experience is one of the most important predictors of achieving optimal socioemotional health, a key facet of infant development. Early social experiences produce neurobiological changes which shape infant brain structure and function, and thereby exert lasting effects on neurodevelopmental outcomes (Weber, Harrison, \& Steward, 2012). During the last trimester of pregnancy, the rate of growth, pruning and plasticity of the infant brain is at its highest, with almost $50 \%$ of neurons in the developing brain experiencing programmed cell death (Dean et al., 2014; Volpe, 2009). Extremely premature infants, those born at 28 weeks gestation or less, are thus hospitalized during this critical period of brain growth, and are exposed to altered social experiences during these first months of life in the highly technological Neonatal Intensive Care Unit (NICU).

Early life experience in the NICU often encompasses maternal separation and limited parental contact that serve as enormous social stressors for the infant (Dageville, Casagrande, De Smet, \& Boutte, 2011; Flacking et al., 2012). Researchers have reported that parents visit their infant in the NICU on average 21 hours per week during hospitalization (Franck \& Spencer, 2003; Gonya \& Nelin, 2013), and that infants are held on average 2 times per week (Reynolds et al., 2013). Thus, extremely premature infants experience the majority of the first months of life without their mother (Greene et al., 2015). The severely stressful social experience of maternal separation places the extremely premature infant at high risk for altered brain development and subsequent deficits in socioemotional skills (Montagna \& Nosarti, 2016).

Researchers have acknowledged the critical need to better understand and address social experiences in extremely premature infants, in light of scientific findings demonstrating impaired socioemotional development in this population (Maroney, 2003; Peralta-Carcelen, Bailey, Rector, \& Gantz, 2013a). Extremely premature infants have higher rates of autism, behavioral problems, negative emotional temperaments, inattention, and other various socioemotional problems when compared with their term peers (Mahoney, Minter, Burch, \& Stapel-Wax, 2013; Montagna \& Nosarti, 2016; Msall \& Park, 2008; Peralta-Carcelen, Bailey, Rector, \& Gantz, 2013b). Differences in socioemotional skills between preterm and term infants can be seen during the early months of life, as premature infants display lower levels of social engagement behaviors during interactions with their mothers (Barnard, Bee, \& Hammond, 1984; Boyd et al., 2013; Brachfeld, Goldberg, \& Sloman, 1980; Crnic, Ragozin, Greenberg, Robinson, \& Basham, 1983; Holditch-Davis, Schwartz, Black, \& Scher, 2007). Moreover, mothers of premature infants display more controlling and less sensitive behaviors than mothers of term infants during the first year of life (Forcada-Guex, Pierrehumbert, Borghini, Moessinger, \& Muller-Nix, 2006; Muller-Nix et al., 2004; Wolke, Eryigit-Madzwamuse, \& Gutbrod, 2014), patterns of behavior that have been associated 
with suboptimal infant development (Rahkonen et al., 2014). In addition to prematurity, maternal-infant characteristics (e.g., education, income, infant illness severity) can present additional risk for negative alterations in interaction behaviors of mothers and premature infants (Brumberg \& Shah, 2015; Holditch-Davis et al., 2007; Linver, Brooks-Gunn, \& Kohen, 2002; White-Traut \& Norr, 2009).

While it is known that early social experiences are critical to infant socioemotional development, the biobehavioral mediators underlying this relationship are less understood. A deep understanding of biobehavioral mediators is necessary to properly assess premature infant responses to social experiences and to determine the efficacy of socially-based interventions long before it is possible to evaluate effects on developmental outcomes. Unlike infants and older children, it can be difficult for clinicians to assess the premature infant's behavioral responses to interventions due to immaturity of their motor systems and their inability to verbalize or communicate behaviorally. Researchers attempting to understand these mediators in the extremely premature infant population are met with measurement challenges. Due to the immaturity of the extremely preterm infant nervous system, infant behaviors, defined as motor movements coordinated in response to external or internal stimuli (Dugatkin, 2012), are often reflexive, non-purposeful, and physiologicallybased (Bougle et al., 1990; Weinstein et al., 2014). Thus, measuring behaviors in this population is difficult because the extremely preterm brain is in the process of developing the sensory-motor fiber tracts that control purposeful movement, i.e., behavior (Cvrčková, Žárský, \& Markoš, 2016; Levitis, Lidicker, \& Freund, 2009; Weinstein et al., 2014). The postmenstrual age (PMA) in which the infant exhibits purposeful social behaviors, as well as the prevalence in which they are exhibited, can vary due to infant medical morbidities and experience with the NICU environment (Pridham et al., 2005; Pridham, Brown, Clark, Sondel, \& Green, 2002). However, typically around 32-34 weeks, social behaviors, such as head turning, mutual gaze, and responsive sucking, consistently emerge (Als, Butler, Kosta, \& McAnulty, 2005; White-Traut \& Norr, 2009). Before this time, display of social behaviors is limited. Thus, a different approach to the measurement of premature infant responses to social experiences is needed.

We propose that the hormone oxytocin (OT) has great potential as a biomarker of the premature infant's responses to social experiences that promote socioemotional health. OT is an affiliation hormone released during supportive social interactions (Feldman, 2012). Increases in human term infant OT levels are associated with increased infant social engagement during parent-infant interaction (Weisman, Zagoory-Sharon, \& Feldman, 2012). OT has not been measured in the premature infant population. In this study, we sought to provide preliminary evidence to support OT as a reliable, sensitive measure of the effects of early social experience in the NICU on socioemotional development in premature infants.

\subsection{Theoretical framework and background}

Schore's Regulation Theory postulates that early life experiences result in a cascade of neurobiological processes which are critical for adequate neuronal network formation, structural brain growth, and brain function (Schore, 2001). Social interaction provides the 
infant with exposure to numerous maternal stimuli. If the social interaction is supportive, then maternal stimuli initiate a series of neurobiological processes that contribute to the emergence of infant self-regulation (Feldman, 2006; Feldman, Eidelman, \& Rotenberg, 2004; Feldman, Weller, Sirota, \& Eidelman, 2002; Weber et al., 2012). An example of these processes is activation of the OT system (Feldman, 2015), which coordinates with the social engagement system to produce the physiologic states, e.g., regulated heart rate, breathing rate, oxygenation, blood pressure,- - or in the cases of a stimulating interaction, infant arousal (Kemp et al., 2012; Norman et al., 2011) and engagement behaviors (Apter-Levi, Zagoory-Sharon, \& Feldman, 2014; Putnam, Roman, Zimmerman, \& Gothard, 2016) that define a sensitive, supportive social interaction between the dyad (Porges, 2003b). Infant engagement behaviors are elicited by neuromuscular innervations of the social engagement system (Porges, 2003a; Porges, 2003b; Porges, 2009), including eyelid opening (eye muscles), vocalizations (larynx/pharynx), head turning toward a mother's voice (neck muscles), calming (vagal nerve), and facial expressions (facial muscles).

Before extremely premature infants begin to display social engagement behaviors, we propose that they socially interact and engage parents with their physiology. Before sociobehavioral rhythms can be established, physiologic rhythms must be intact (Feldman, 2006; Feldman, Monakhov, Pratt, \& Ebstein, 2015; Ulmer-Yaniv et al., 2016). Through repeated and consistent daily interactions, the mother exposes her infant to repeated and consistent neurobiological events that significantly contribute to the emergence of social behaviors (Feldman, 2006; Weber et al., 2012). A significant strength of researching the OT system includes the possible opportunity to measure the socially-based neurobiological antecedents of the social behaviors (e.g., mutual gaze, comforting touch, soft vocalizations) that define social interactions, construct the mother-infant relationship, and promote infant socioemotional development (Feldman, 2015).

Researchers have not investigated the relationship between the proposed antecedent, OT, and subsequent social engagement behaviors in premature infants. The purpose of this exploratory study was to examine associations between infant plasma OT levels during the early period of behavioral immaturity and emerging social engagement behaviors later in gestation. We developed several working hypotheses surrounding social engagement behaviors during maternal-infant interaction:

- $\quad$ Higher infant plasma OT trajectories (higher intercepts and steeper slopes) are associated with greater infant and parent social engagement behaviors.

- $\quad$ Greater parent social engagement behaviors are associated with greater infant social engagement behaviors.

- Maternal demographics (age, education, income, parity, marital status) are associated with maternal social engagement behaviors.

- Infant demographics (gestational age, birthweight, neurobiological risk) are associated with infant social engagement behaviors during maternal-infant interaction. 


\section{Method}

\subsection{Participants}

The study sample of 28 extremely premature infants was derived from a larger sample of infants $(n=37)$ recruited from three Midwestern Level III NICUs. This subset was used because these infants had complete data on social engagement, the behaviors required for analysis. Inclusion criteria included English-speaking mothers who gave birth to premature infants ranging from 25 to 28 6/7 weeks gestation. Subjects were included in this age range to minimize attrition due to death or severe complications from prematurity closest to the borderline of viability. The age range also allowed for a comprehensive investigation of the trajectory of plasma OT levels throughout the course of early brain development. Exclusion criteria were chosen due to their influence on infant brain development and/or neurobiological processes: history of maternal drug abuse (Ornoy, 2003; Thompson, Levitt, \& Stanwood, 2009), presence of major congenital or chromosomal abnormality, grade 3 or 4 intraventricular hemorrhage (Bolisetty et al., 2013), hypoxic ischemic encephalopathy (Logitharajah, Rutherford, \& Cowan, 2009), metabolic disorders involving the adrenal system (Khulan \& Drake, 2012) and necrotizing enterocolitis requiring surgical intervention (Ta et al., 2011).

Power analysis was conducted for a larger study to determine adequate sample size for detecting change in OT trajectories in extremely premature infants. Because power calculations were not conducted for the aims of this manuscript, we did not determine a priori whether these analyses with 28 infants had adequate power. In the results of this paper, we discuss a post hoc power analysis to address power for this study.

\subsection{Procedure}

Mothers were recruited during the first 2 weeks of life by direct approach from the PI. All participating mothers signed a written consent form approved by the institutional review boards of the academic institution and participating clinical sites. Sample collection started on approximately Day of Life 14, then commenced weekly until the infant achieved 34 PMA. Sample collections occurred between the hours of 2300 and 0200 to control for the potential diurnal variation of OT. Blood collection occurred by heelstick unless the infant had an arterial line, and was concurrent with blood draws required for clinical treatment. Blood was collected into chilled EDTA ( $1 \mathrm{mg} / \mathrm{ml}$ ) BD microtainer tubes (Becton, Dickson, \& Company, USA) containing Aaprotininprotinin $(10 \mu \mathrm{L} / \mathrm{mL}$ of blood). All samples were collected before feeding as OT levels are reported to be influenced by the act of suckling (Lupoli, Johansson, Uvnäs-Moberg, \& Svennersten-Sjaunja, 2001) and digestion (Verbalis, Blackburn, Hoffman, \& Stricker, 1995; Verbalis, McCann, McHale, \& Stricker, 1986). After collection, samples were immediately placed on ice, processed, and transferred to a locked $-80{ }^{\circ} \mathrm{C}$ freezer.

Infant social engagement behaviors were measured during a videotaped feeding when the infant was receiving at least $25 \%$ of daily enteral nutrition through nipple feeding. The first 5 minutes of a video-taped feeding task was scored, because we believed infants would initially display engagement behaviors before becoming fatigued during feeding. Videotaped 
feedings were scheduled to take place at the infant's bedside, during a time when mothers had already intended to visit and feed their baby in the NICU. Thus, times in which the videotaped feedings took place varied by baby. We also scheduled the videotaped feedings after mothers had already been regularly feeding their infants, to control for differences in maternal experience with premature infant feeding. However, because some mothers were only able to visit their infants a few times during NICU hospitalization, this was not always possible. If deemed safe by the infant's bedside nurse, doors and curtains were closed to maintain privacy of the dyad and minimize distractions.

\subsection{Measures}

2.3.1. Plasma OT_Plasma OT was measured using an extraction-free, commercially available kit (Peninsula Laboratories International, Inc., San Carlos, CA, KIT S-1355.0001). Samples were not extracted due to safety and ethical concerns of taking larger amounts of body fluids from medically-fragile infants. Samples were immediately placed on ice, transported, then centrifuged at $4{ }^{\circ} \mathrm{C}$ at $2000 \mathrm{~g}$ for $10 \mathrm{~min}$ within $1 \mathrm{~h}$ of collection. Supernatants were collected, stored at $-80^{\circ} \mathrm{C}$, and assayed in batches to minimize time spent in storage. Samples from the same infant were assayed simultaneously to avoid interassay variation. All measurements were performed in duplicate. Intra-assay coefficients of variation were found to be $12 \%$.

2.3.2. Infant and parent social engagement behaviors-Infant and parent social engagement behaviors were measured using the well-validated Parent-Child Early Relational Assessment (PCERA; Clark, 2010), an assessment tool with subscales assessing observable behavior and affect of parent, infant, and dyad. The PCERA has been tested, validated, and used with both term and preterm infants (Clark, 1999; Poehlmann et al., 2012; Poehlmann et al., 2011). Each item consists of an ordinal, 5-point Likert-type scale in which 5 is the most positive score (Clark, 2010). Scores of 1 or 2 indicate areas of clinical concern, scores of 3 indicate areas of some concern, and scores of 4 or 5 indicate areas of strength. For the purposes of this study, only the infant and parent subscales of Positive Affect and Behavior were used, precisely because these scales measure social engagement behaviors during interaction. Examples of infant items include alertness during the interaction, social responsiveness, visual contact, and demonstration of exploring the environment. Examples of parent items include positive affect, tone of voice, physical contact, sensitivity, and connectedness with the infant. Interrater reliability was assessed by independent viewing of $20 \%$ of the tapes by two raters and was calculated at $91 \%$ agreement (i.e., proportion of exact agreement), with an average calculated intraclass correlation coefficient (ICC) of 0.79 (i.e., strong agreement). Raters were blinded to all study data and had no interaction with participants. Subscale score was computed as the average of the sum of each scale's items (11 infant items, 16 parent items).

2.3.3. Neurobiological risk-Neurobiological risk was measured using the Neurobiological Risk Score (NBRS), a well validated predictor of neurodevelopmental outcomes that is strongly correlated with the Bayley Scales of Infant Development and with abnormal neurologic examination findings (Nunes et al., 1998). Seven items (infection, blood $\mathrm{pH}$, seizures, intraventricular hemorrhage, assisted ventilation, periventricular 
leukomalacia, and hypoglycemia) are scored as $0,1,2$, or 4 and summed, with higher scores indicating greater risk for adverse developmental outcomes. Total scores were calculated during the first 2 weeks of the infant's hospital stay and used for analysis. Infants with a score of $\geq 5$ are considered to be at high risk for poor neurological development (Brazy, Eckerman, Oehler, Goldstein, \& O'Rand, 1991; Brazy, Goldstein, Oehler, Gustafson, \& Thompson, 1993).

2.3.4. Demographics-Demographics for infants and mothers were abstracted from the infants' electronic medical record (EMR). Demographics that could not be verified by the EMR, such as maternal education and income, were collected via parent questionnaire.

\subsection{Data analysis}

To control the Type I error rate, an overall alpha level of 0.05 was chosen for the analyses. We did not lower the alpha level to account for multiple testing due to the exploratory nature of the study. All OT levels were logged, due to the skewed distribution of the data. For the first hypothesis, a linear mixed model was used to evaluate associations between infant OT levels, the dependent variable, and social engagement behaviors. The model was:

$Y_{i t}=\beta_{0}+\beta_{1}($ social engagement $)+\beta_{2}\left(\right.$ Age $\left._{i t}-27\right)+\beta_{3}($ social engagement $) \times\left(\right.$ Age $\left._{i t}-27\right)+b_{0 i} i+b_{1 i} \times\left(\right.$ Age $\left._{i t}-27\right)+\varepsilon_{i t}$

In the model, $i$ indexes the infant, $t$ the postmenstrual age. The $\beta$ terms are fixed effects. The two $b$ terms $\left(b_{0 i}, b_{1 i}\right)$ are random effects, which adjust the mean parameters for infantspecific variation in OT trajectory. Age ${ }_{i t}$, which was modeled as a continuous variable centered at 27 weeks PMA, is the postmenstrual age for infant $i$ when plasma OT was measured at time $t$. We included interaction terms of social engagement behaviors with age in order to examine associations between social engagement and the developmental trajectory (i.e., slope) of OT levels. The effects of engagement behaviors for infants and mothers were assessed in independent models. In both models, we controlled for gestational age at birth, birthweight, neurobiological risk score, and corrected age at videotaped feeding as intercept effects.

For the remainder of the hypotheses, we used multiple linear regressions and controlled for a limited number of covariates in order to conserve power. To test the second hypothesis, we assessed the relationship between infant and maternal social engagement behaviors. Infant behaviors were the dependent variable, maternal behaviors the independent variable, and the covariates added were maternal age, education, income, and parity. To test the third hypothesis that maternal demographics are related to maternal social engagement behaviors, we used a model in which maternal behaviors was the dependent variable, and the independent variables were maternal age, education, income, and parity. To test the fourth hypothesis that infant demographics are related to infant social engagement behaviors, we used a model in which infant behaviors was the dependent variable, and the independent variables were infant gestational age, birthweight, and neurobiological risk. 


\section{Results}

Demographic and descriptive statistics for the sample are displayed in Tables 1 and 2.

As seen in Table 2, the mean of infant engagement behaviors, as measured by the Infant Positive Affect and Behavior Subscale of the PCERA, was categorized as having "Clinical Concern" (mean $=2.85, \mathrm{SD}=0.62)$. The mean of maternal engagement behaviors was categorized as having "Some Concern" (mean $=3.24$, SD 0.71). Interactions of social engagement behaviors and age were not significant, and thus were not included in the final models. The results of the first aim revealed a significant, yet negative association between infant plasma OT levels and infant social engagement behaviors when controlling for key covariates as intercept effects (Table 3).

The association was also substantial, as a one-point increase in infant social engagement was associated with a decrease of nearly one-third in logged plasma OT levels $(b=-0.32 ; p=$ $0.01,95 \%$ CI: -0.57 to -0.07$)$. However, there was no association between infant plasma OT levels and maternal social engagement behaviors (results not shown; $b=-0.04 ; p=0.73$, 95\% CI: -0.28 to 0.19 ), even when controlling for gestational age at birth, birthweight, NBRS, and age at videotaping as intercept effects. Results of the second aim revealed that higher maternal social engagement was associated with higher infant social engagement, even when controlling for maternal age, education, income, parity, and marital status (Table $4)$.

Results of the third aim revealed that only maternal parity was related to maternal social engagement ( $b=-0.29 ; p=0.02,95 \% \mathrm{CI}:-0.52$ to -0.05 ), with higher number of births being associated with lower maternal social engagement (Table 5).

To ensure that this result was not due to high correlations among maternal demographics, we regressed each maternal demographic separately with maternal social engagement, and confirmed that only maternal parity was related to maternal social engagement. Finally, results of the fourth aim revealed that infant gestational age $(b=0.02 ; p=0.88,95 \% \mathrm{CI}$ : -0.29 to 0.33 ), birthweight ( $b=-0.0002 ; p=0.74,95 \% \mathrm{CI}:-0.001$ to 0.001 ), and neurobiological risk ( $b=0.04 ; p=0.40,95 \% \mathrm{CI}$ : -0.06 to 0.15 ) were not associated with infant social engagement. These nonsignificant associations remained even after controlling for infant PMA at videotaping.

\section{Discussion}

To summarize this study's results, infant plasma OT levels were negatively associated with infant social engagement behaviors, but not associated with maternal social engagement behaviors (Aim 1), infant social engagement behaviors were associated with maternal social engagement behaviors (Aim 2), only maternal parity was related to maternal social engagement (Aim 3), and infant characteristics were not related to infant social engagement (Aim 4).

We found the average levels of infant social engagement behaviors as measured in this study were categorized as being "Clinically Concerning". It can be difficult to observe social 
engagement behaviors during feedings, because the premature infant is focused on coordination of the suck-swallow-breathe mechanism, as opposed to interacting with the parent (Thoyre \& Brown, 2004; Thoyre, Hubbard, Park, Pridham, \& McKechnie, 2016). The premature infant may attempt to block any extraneous stimuli, such as stimuli from maternal social engagement behaviors, in an effort to maintain physiologic stability during feeding (Thoyre \& Brown, 2004; Thoyre \& Carlson, 2003; Weber \& Harrison, 2014). PCERA scoring focuses on observable interaction behaviors that require enormous energy expenditure, but can still be seen before term equivalent age (i.e., 40 weeks PMA): eye opening, purposeful motor movements toward caregiver, synchronous gaze, and head turning toward caregiver (Clark, 1999). The extremely premature infant may not display these behaviors during feeding in an effort to conserve energy, promote physiologic stability, and ensure safe consumption of milk. In future research designs, changing the context of the interaction to an activity that does not require a significant amount of energy, such as a diaper change, may allow a premature infant to expend more energy on exhibiting social engagement behaviors during maternal-infant interaction. Future research should also consider using serial measures of maternal-infant interaction to assess developmental change over time and also gain information about individual stability of dyadic interaction styles. The finding of low infant engagement levels during feeding echoes the clinical recommendations of others, who encourage the use of anticipatory guidance to inform mothers of the possibility of low infant social engagement and to encourage matching the infant's readiness cues for engagement to minimize overstimulation during feeding (Thoyre et al., 2016; Thoyre, Shaker, \& Pridham, 2005).

This exploratory study is the first to investigate associations between OT levels and social engagement behaviors in extremely premature infants. An unexpected finding was the significant, negative relationship between infant plasma OT levels and infant social engagement. Previous research has shown that in healthy, term-born infants (Feldman, Gordon, \& Zagoory-Sharon, 2010; Weisman et al., 2012) and children (Feldman, Golan, Hirschler-Guttenberg, Ostfeld-Etzion, \& Zagoory-Sharon, 2014; Feldman, Gordon, Influs, Gutbir, \& Ebstein, 2013; Pratt et al., 2015), salivary OT levels increase after social interaction with their parents. These same studies also showed that higher infant salivary basal OT levels, as well as OT reactivity to social interaction (i.e., changes in OT levels pre/ post social interaction), were related to greater social engagement during infancy (Feldman et al., 2010; Weisman et al., 2012). However, these research studies used serial measurements immediately before and after social interaction, as opposed to this study's design, which obtained basal levels well before assessment of engagement behaviors.

One must consider OT dysregulation in the premature infant population as one possible explanation for this study's unexpected findings. Populations characterized by low levels of social engagement, such as depressed mothers (Apter-Levy, Feldman, Vakart, Ebstein, \& Feldman, 2013; Pratt et al., 2015), persons with autism (Feldman et al., 2014; Husarova et al., 2016), and patients with schizophrenia (Jobst et al., 2014; Rubin et al., 2010) have lower basal OT levels than healthy controls. Future research should compare OT responses in extremely premature infants and term infants before and after social interaction to determine if there are differences in basal OT levels and/or OT reactivity between the two groups. A positive relationship between OT levels and social engagement behaviors may be restored in 
premature infants after interaction due to regulation by the parent. This was the finding in autistic preschoolers, whose low basal levels of salivary OT returned to normal after $45 \mathrm{~min}$ of physical contact with a parent (Feldman et al., 2014). Furthermore, the finding that parent social engagement behaviors, a possible indicator of the quality of maternal interaction that the infants had been receiving in the NICU, were not related to basal levels of OT, may also be a sign of early OT dysregulation in premature infants. Autistic children have low basal levels of OT, despite experiencing similar levels of parental sensitivity as typicallydeveloping peers (Oppenheim, Koren-Karie, Dolev, \& Yirmiya, 2012), yet their OT reactivity to physical contact, and the magnitude of that reactivity in relationship to parentinfant synchrony, is intact (Feldman et al., 2014). Like autistic children, it is possible that while basal levels of OT are not related to maternal engagement behaviors, the magnitude of OT reactivity is related to maternal engagement in premature infants. Because this sample of mothers demonstrated "Some Concern" with their engagement levels, and premature infants have been shown to not receive the same sensitive maternal caregiving as term peers in some studies (Feldman \& Eidelman, 2006; Forcada-Guex et al., 2006; Muller-Nix et al., 2004; Wolke et al., 2014), comparison of findings with autistic children should be made with caution.

Nevertheless, our theory that basal OT dysregulation and normal OT reactivity (i.e., an increase in OT levels following supportive social interaction) may describe the OT function of premature infants warrants further investigation in light of the findings supporting the second hypothesis that increases in parent social engagement behaviors were related to increases in infant social engagement behaviors. This is an exciting finding, given that social engagement behaviors were measured so early in the socioemotional development of these infants. Previous research has reported significant, positive associations between maternal and premature infant interaction behaviors, but these studies were conducted much later in development and after NICU hospitalization (Feldman \& Eidelman, 2006; Sansavini et al., 2015). Our research suggests that during the early period of infant socio-behavioral development, premature infants are behaviorally reactive to the social engagement behaviors of their mothers. Given this behavioral reactivity to mothers, it is also possible that the infant's OT reactivity is present during interaction, and future research is needed to confirm this hypothesis.

Contrary to the third and fourth hypotheses, maternal and infant demographics were minimally related to social engagement behaviors. Only maternal parity was significantly and negatively related to a mother's social engagement behaviors during interaction. Previous research has also associated higher maternal parity with less positive involvement (Holditch-Davis et al., 2007), perhaps due to increased stress and responsibilities of caregiving for other children. Maternal demographics have been related to measures of maternal interaction in previous decades of research (Belsky, 1984; Chin-Lun Hung et al., 2015; Conger \& Donnellan, 2007; Seifer, Sameroff, Anagnostopolou, \& Elias, 1992), but it is possible that in this study's sample other unmeasured maternal characteristics, such as stress, anxiety, and depression, had more influence on the social engagement of the mother.

Previous research with premature infants has shown significant relationships among gestational age, birthweight, medical risk and infant social engagement (Feldman \& 
Eidelman, 2006). However, this research enrolled premature infants with higher and more variable birthweights and gestational ages than those enrolled in the current study. It is difficult to compare our study with other studies that have found relationships between infant characteristics and infant social engagement (Muller-Nix et al., 2004; Neri, Agostini, Salvatori, Biasini, \& Monti, 2015), because these studies enrolled both preterm and term infants, and thus also had more variability in characteristics such as infant birthweight and gestational age at birth. It is possible that because the final sample consisted of extremely or very low birthweight infants born within a narrow gestational age window, our study could not detect these relationships.

There are several limitations with this exploratory study. First, we enrolled a small sample, which limits the generalizability of the findings, the number of covariates we could control for in our statistical analyses, and potentially the ability to detect statistically significant effects. Partially to address this concern, we conducted a post hoc power analysis for maternal social engagement as a predictor of infant plasma OT levels. This analysis, conducted with the parameter estimates of the fitted model and the mean/standard deviations of maternal engagement, revealed that a sample of 28 mother-infant dyads would have $80 \%$ power to detect an effect size (i.e., beta coefficient) of -0.22 , which is significantly larger than the observed effect size of $\beta=-0.04$ for maternal social engagement. Second, because we did not enroll healthy term infants, we did not have the opportunity to compare our results with a normative population. Moreover, we did not include maternal measures of stress, anxiety, depression, and OT levels, several variables that have been shown to affect a child's OT levels and social engagement (Mah, 2016; Pratt et al., 2015). However, the innovation of this study is a significant strength, as the results add several new findings to the growing body of OT research. This study was the first to find a relationship between plasma OT and social engagement behaviors during the early period in which social behaviors emerge during infancy. Furthermore, this study demonstrated relationships between maternal and infant social engagement behaviors in a highly vulnerable infant population, during a period of time in which it can be developmentally and physiologically difficult for these infants to display such complex engagement behaviors. This study provides a foundation for future research that may measure OT as a neurobiological antecedent to social engagement, especially in populations where measurement of behaviors is limited due to developmental or medical conditions.

\section{Conclusion}

Infants transition from the physiologic to the sociobehavioral world during the first 3 months after birth — the period in which extremely premature infants are hospitalized in the NICU. Understanding OT and other neurobiological antecedents that facilitate this transition provides a more complete picture of socioemotional development. Moreover, adding OT to a researcher's repertoire of biomarkers extends investigations of the effects of early social experiences on infant outcomes into earlier periods of human development. Finally, OT research with premature infants may result in new ways of identifying socially-based interventions that impact the neurobiological antecedents of optimal socioemotional health in other vulnerable infant populations. This study represents the start in this important aspect 
of OT research by demonstrating associations between the neurobiological antecedent, OT, and social engagement in extremely premature infants during their NICU hospitalization.

\section{Acknowledgments}

Funding: This work was supported by the National Institutes of Health NINR NRSA (F31NR-014985), a Postdoctoral Fellowship from NINR 1T32NR015433-01, AWHONN and the Every Woman, Every Baby Campaign, the Epsilon Chapter of Sigma Theta Tau, Ohio Nurses Foundation, Sigma Theta Tau International in partnership with the Midwestern Nursing Research Society, National Association of Neonatal Nurses Small Grants program, Nurses Educational Funds, the Ohio Perinatal Research Network (OPRN), and The Graduate School, Ohio State University's Alumni Grants for Graduate Research and Scholarship (AGGRS).

The authors would like to thank Dr. Mary Cismowski for generously providing her time to assay the samples required for this research. The authors would also like to thank Dr. Courtney DeVries for her mentorship and critical appraisal of this research project.

\section{References}

Als H, Butler S, Kosta S, McAnulty G. The Assessment of Preterm Infants' Behavior (APIB): Furthering the understanding and measurement of neurodevelopmental competence in preterm and full-term infants. Mental Retardation and Developmental Disabilities Research Reviews. 2005; 11(1):94-102. http://dx.doi.org/10.1002/mrdd.20053. [PubMed: 15856436]

Apter-Levi Y, Zagoory-Sharon O, Feldman R. Oxytocin and vasopressin support distinct configurations of social synchrony. Brain Research. 2014; 1580:124-132. http://dx.doi.org/10.1016/ j.brainres.2013.10.052. [PubMed: 24184577]

Apter-Levy Y, Feldman M, Vakart A, Ebstein RP, Feldman R. Impact of maternal depression across the first 6 years of life on the child's mental health, social engagement, and empathy: The moderating role of oxytocin. The American Journal of Psychiatry. 2013; 170(10):1161-1168. http://dx.doi.org/ 10.1176/appi.ajp.2013.12121597. [PubMed: 23846912]

Barnard KE, Bee HL, Hammond MA. Developmental changes in maternal interactions with term and preterm infants. Infant Behavior and Development. 1984; 7(1):101-113. http://dx.doi.org/10.1016/ S0163-6383(84)80026-0.

Belsky J. The determinants of parenting: A process model. Child Development. 1984; 55(1):83-96. [PubMed: 6705636]

Bolisetty, S., Dhawan, A., Abdel-Latif, M., Bajuk, B., Stack, J., Lui, K. Collection, on behalf of the N. S. W. and A. C. T. N. I. C. U. D. Intraventricular hemorrhage and neurodevelopmental outcomes in extreme preterm infants. Pediatrics. 2013. http://dx.doi.org/10.1542/peds.2013-0372

Bougle D, Denise P, Yaseen H, Tranier S, Voirin J, Pottier M, Venezia R. Maturation of peripheral nerves in preterm infants. Motor and proprioceptive nerve conduction. Electroencephalography and Clinical Neurophysiology. 1990; 75(2):118-121. [PubMed: 1688767]

Boyd LA, Msall ME, O'Shea TM, Allred EN, Hounshell G, Leviton A. Social-emotional delays at 2 years in extremely low gestational age survivors: Correlates of impaired orientation/engagement and emotional regulation. Early Human Development. 2013; 89(2):925-930. http://dx.doi.org/10.1016/ j.earlhumdev.2013.09.019. [PubMed: 24144915]

Brachfeld S, Goldberg S, Sloman J. Parent-infant interaction in free play at 8 and 12 months: Effects of prematurity and immaturity. Infant Behavior and Development. 1980; 3:289-305. http:// dx.doi.org/10.1016/S0163-6383(80)80038-5.

Brazy JE, Eckerman CO, Oehler JM, Goldstein RF, O’Rand AM. Nursery Neurobiologic Risk Score: Important factor in predicting outcome in very low birth weight infants. The Journal of Pediatrics. 1991; 118(5):783-792. [PubMed: 2019935]

Brazy JE, Goldstein RF, Oehler JM, Gustafson KE, Thompson RJ Jr. Nursery Neurobiologic Risk Score: Levels of risk and relationships with nonmedical factors. Journal of Developmental and Behavioral Pediatrics: JDBP. 1993; 14(6):375-380. [PubMed: 8126229] 
Brumberg HL, Shah SI. Born early and born poor: An eco-bio-developmental model for poverty and preterm birth. Journal of Neonatal-Perinatal Medicine. 2015; 8(3):179-187. http://dx.doi.org/ 10.3233/NPM-15814098. [PubMed: 26485551]

Chin-Lun Hung G, Hahn J, Alamiri B, Buka SL, Goldstein JM, Laird NM, ... Gilman SE. Socioeconomic disadvantage and neural development from infancy through early childhood. International Journal of Epidemiology. 2015; 44(6):1889-1899. http://dx.doi.org/10.1093/ije/ dyv303. [PubMed: 26675752]

Clark R. The Parent-Child Early Relational Assessment: A factorial validity study. Educational and Psychological Measurement. 1999; 59(5):821-846. http://dx.doi.org/ 10.1177/00131649921970161.

Clark, R. The Parent Child Early Relational Assessment manual. University of Wisconsin-Madison College of Nursing; 2010.

Conger RD, Donnellan MB. An interactionist perspective on the socioeconomic context of human development. Annual Review of Psychology. 2007; 58:175-199. http://dx.doi.org/10.1146/ annurev.psych.58.110405.085551.

Crnic KA, Ragozin AS, Greenberg MT, Robinson NM, Basham RB. Social interaction and developmental competence of preterm and full-term infants during the first year of life. Child Development. 1983; 54(5):1199-1210. [PubMed: 6354627]

Cvrčková F, Žárský V, Markoš A. Plant studies may lead us to rethink the concept of behavior. Frontiers in Psychology. 2016; 7 http://dx.doi.org/10.3389/fpsyg.2016.00622.

Dageville C, Casagrande F, De Smet S, Boutte P. The mother-infant encounter at birth must be protected. Archives de Pediatrie. 2011; 18(9):994-1000. http://dx.doi.org/10.1016/j.arcped. 2011.06.007. [PubMed: 21820284]

Dean JM, Bennet L, Back SA, McClendon E, Riddle A, Gunn AJ. What brakes the preterm brain? An arresting story. Pediatric Research. 2014; 75(1-2):227-233. http://dx.doi.org/10.1038/pr.2013.189. [PubMed: 24336432]

Dugatkin, LA. What is "behavior" anyway?. 2012 Jul 17. Retrieved March 23, 2016, from http:// www.psychologytoday.com/blog/the-prince-evolution/201207/what-is-behavior-anyway

Feldman R. From biological rhythms to social rhythms: Physiological precursors of mother-infant synchrony. Developmental Psychology. 2006; 42(1):175-188. http://dx.doi.org/ 10.1037/0012-1649.42.1.175. [PubMed: 16420127]

Feldman R. Oxytocin and social affiliation in humans. Hormones and Behavior. 2012; 61(3):380-391. http://dx.doi.org/10.1016/j.yhbeh.2012.01.008. [PubMed: 22285934]

Feldman R. Sensitive periods in human social development: New insights from research on oxytocin, synchrony, and high-risk parenting. Development and Psychopathology. 2015; 27(2):369-395. http://dx.doi.org/10.1017/S0954579415000048. [PubMed: 25997760]

Feldman R, Eidelman AI. Neonatal state organization, neuromaturation, mother-infant interaction, and cognitive development in small-for-gestational-age premature infants. Pediatrics. 2006; 118(3):e869-e878. http://dx.doi.org/10.1542/peds.2005-2040. [PubMed: 16880249]

Feldman R, Eidelman AI, Rotenberg N. Parenting stress, infant emotion regulation, maternal sensitivity, and the cognitive development of triplets: A model for parent and child influences in a unique ecology. Child Development. 2004; 75(6):1774-1791. http://dx.doi.org/10.1111/j. 1467-8624.2004.00816.x. [PubMed: 15566379]

Feldman R, Golan O, Hirschler-Guttenberg Y, Ostfeld-Etzion S, Zagoory-Sharon O. Parent-child interaction and oxytocin production in pre-schoolers with autism spectrum disorder. The British Journal of Psychiatry. 2014; 205(2):107-112. http://dx.doi.org/10.1192/bjp.bp.113.137513. [PubMed: 24855128]

Feldman R, Gordon I, Influs M, Gutbir T, Ebstein RP. Parental oxytocin and early caregiving jointly shape children's oxytocin response and social reciprocity. Neuropsychopharmacology. 2013; 38(7):1154-1162. http://dx.doi.org/10.1038/npp.2013.22. [PubMed: 23325323]

Feldman R, Gordon I, Zagoory-Sharon O. The cross-generation transmission of oxytocin in humans. Hormones and Behavior. 2010; 58(4):669-676. http://dx.doi.org/10.1016/j.yhbeh.2010.06.005. [PubMed: 20558167] 
Feldman, R., Monakhov, M., Pratt, M., Ebstein, RP. Oxytocin pathway genes: Evolutionary ancient system impacting on human affiliation, sociality, and psychopathology. Biological Psychiatry. 2015. http://dx.doi.org/10.1016/j.biopsych.2015.08.008

Feldman R, Weller A, Sirota L, Eidelman AI. Skin-to-skin contact (Kangaroo care) promotes selfregulation in premature infants: Sleep-wake cyclicity, arousal modulation, and sustained exploration. Developmental Psychology. 2002; 38(2):194-207. [PubMed: 11881756]

Flacking R, Lehtonen L, Thomson G, Axelin A, Ahlqvist S, Moran VH, ... Dykes F. Closeness and separation in neonatal intensive care. Acta Paediatrica (Oslo, Norway: 1992). 2012; 101(10):10321037. http://dx.doi.org/10.1111/j.1651-2227.2012.02787.x.

Forcada-Guex M, Pierrehumbert B, Borghini A, Moessinger A, Muller-Nix C. Early dyadic patterns of mother-infant interactions and outcomes of prematurity at 18 months. Pediatrics. 2006; 118(1):e107-e114. http://dx.doi.org/10.1542/peds.2005-1145. [PubMed: 16818525]

Franck LS, Spencer C. Parent visiting and participation in infant caregiving activities in a neonatal unit. Birth (Berkeley, Calif). 2003; 30(1):31-35.

Gonya J, Nelin LD. Factors associated with maternal visitation and participation in skin-to-skin care in an all referral level IIIc NICU. Acta Paediatrica (Oslo, Norway: 1992). 2013; 102(2):e53-e56. http://dx.doi.org/10.1111/apa.12064.

Greene MM, Rossman B, Patra K, Kratovil A, Khan S, Meier PP. Maternal psychological distress and visitation to the neonatal intensive care unit. Acta Paediatrica (Oslo, Norway: 1992). 2015; 104(7):e306-e313. http://dx.doi.org/10.1111/apa.12975.

Holditch-Davis D, Schwartz T, Black B, Scher M. Correlates of mother-premature infant interactions. Research in Nursing \& Health. 2007; 30(3):333-346. http://dx.doi.org/10.1002/nur.20190. [PubMed: 17514707]

Husarova VM, Lakatosova S, Pivovarciova A, Babinska K, Bakos J, Durdiakova J, ... Ostatnikova D. Plasma oxytocin in children with autism and its correlations with behavioral parameters in children and parents. Psychiatry Investigation. 2016; 13(2):174-183. http://dx.doi.org/10.4306/pi. 2016.13.2.174. [PubMed: 27081377]

Jobst A, Dehning S, Ruf S, Notz T, Buchheim A, Henning-Fast K, ... Zill P. Oxytocin and vasopressin levels are decreased in the plasma of male schizophrenia patients. Acta Neuropsychiatrica. 2014; 26(6):347-355. http://dx.doi.org/10.1017/neu.2014.20. [PubMed: 25288094]

Kemp AH, Quintana DS, Kuhnert RL, Griffiths K, Hickie IB, Guastella AJ. Oxytocin increases heart rate variability in humans at rest: Implications for social approach-related motivation and capacity for social engagement. PLoS One. 2012; 7(8):e44014. http://dx.doi.org/10.1371/journal.pone. 0044014. [PubMed: 22937145]

Khulan B, Drake AJ. Glucocorticoids as mediators of developmental programming effects. Best Practice \& Research. Clinical Endocrinology \& Metabolism. 2012; 26(5):689-700. http:// dx.doi.org/10.1016/j.beem.2012.03.007. [PubMed: 22980050]

Levitis DA, Lidicker WZ, Freund G. Behavioural biologists don't agree on what constitutes behaviour. Animal Behaviour. 2009; 78(1):103-110. http://dx.doi.org/10.1016/j.anbehav.2009.03.018. [PubMed: 20160973]

Linver MR, Brooks-Gunn J, Kohen DE. Family processes as pathways from income to young children's development. Developmental Psychology. 2002; 38(5):719-734. [PubMed: 12220050]

Logitharajah P, Rutherford MA, Cowan FM. Hypoxic-ischemic encephalopathy in preterm infants: Antecedent factors, brain imaging, and outcome. Pediatric Research. 2009; 66(2):222-229. http:// dx.doi.org/10.1203/PDR.0b013e3181a9ef34. [PubMed: 19390490]

Lupoli B, Johansson B, Uvnäs-Moberg K, Svennersten-Sjaunja K. Effect of suckling on the release of oxytocin, prolactin, cortisol, gastrin, cholecystokinin, somatostatin and insulin in dairy cows and their calves. The Journal of Dairy Research. 2001; 68(2):175-187. [PubMed: 11504382]

Mah BL. Oxytocin, postnatal depression, and parenting: A systematic review. Harvard Review of Psychiatry. 2016; 24(1):1-13. http://dx.doi.org/10.1097/HRP.0000000000000093. [PubMed: 26735320]

Mahoney AD, Minter B, Burch K, Stapel-Wax J. Autism spectrum disorders and prematurity: A review across gestational age subgroups. Advances in Neonatal Care. 2013; 13(4):247-251. http:// dx.doi.org/10.1097/ANC.0b013e31828d02a1. [PubMed: 23912016] 
Maroney DI. Recognizing the potential effect of stress and trauma on premature infants in the NICU: How are outcomes affected? Journal of Perinatology. 2003; 23(8):679-683. http://dx.doi.org/ 10.1038/sj.jp.7211010. [PubMed: 14647168]

Montagna A, Nosarti C. Socio-emotional development following very preterm birth: Pathways to psychopathology. Frontiers in Psychology. 2016; 7 http://dx.doi.org/10.3389/fpsyg.2016.00080.

Msall ME, Park JJ. The spectrum of behavioral outcomes after extreme prematurity: Regulatory, attention, social, and adaptive dimensions. Seminars in Perinatology. 2008; 32(1):42-50. http:// dx.doi.org/10.1053/j.semperi.2007.12.006. [PubMed: 18249239]

Muller-Nix C, Forcada-Guex M, Pierrehumbert B, Jaunin L, Borghini A, Ansermet F. Prematurity, maternal stress and mother-child interactions. Early Human Development. 2004; 79(2):145-158. http://dx.doi.org/10.1016/j.earlhumdev.2004.05.002. [PubMed: 15324994]

Neri E, Agostini F, Salvatori P, Biasini A, Monti F. Mother-preterm infant interactions at 3 months of corrected age: Influence of maternal depression, anxiety and neonatal birth weight. Frontiers in Psychology. 2015; 6 http://dx.doi.org/10.3389/fpsyg.2015.01234.

Norman GJ, Cacioppo JT, Morris JS, Malarkey WB, Berntson GG, Devries AC. Oxytocin increases autonomic cardiac control: Moderation by loneliness. Biological Psychology. 2011; 86(3):174180. http://dx.doi.org/10.1016/j.biopsycho.2010.11.006. [PubMed: 21126557]

Nunes A, Melo F, Silva JE, Costa A, Bispo MA, Palminha JM. Importance of J. Brazy's neurobiological index. Prediction of the number and severity of complications in very low birth weight infants. Acta Medica Portuguesa. 1998; 11(7):615-621. [PubMed: 9859506]

Oppenheim D, Koren-Karie N, Dolev S, Yirmiya N. Maternal sensitivity mediates the link between maternal insightfulness/resolution and child-mother attachment: The case of children with Autism Spectrum Disorder. Attachment \& Human Development. 2012; 14(6):567-584. http://dx.doi.org/ 10.1080/14616734.2012.727256. [PubMed: 23106179]

Ornoy A. The impact of intrauterine exposure versus postnatal environment in neurodevelopmental toxicity: Long-term neurobehavioral studies in children at risk for developmental disorders. Toxicology Letters. 2003; 140-141:171-181.

Peralta-Carcelen M, Bailey K, Rector R, Gantz M. Behavioral and socioemotional competence problems of extremely low birth weight children. Journal of Perinatology. 2013a; 33(11):887-892. http://dx.doi.org/10.1038/jp.2013.78. [PubMed: 23867957]

Peralta-Carcelen, M., Bailey, K., Rector, R., Gantz, M. Behavioral and socioemotional competence problems of extremely low birth weight children. Journal of Perinatology. 2013b. http://dx.doi.org/ 10.1038/jp.2013.78

Poehlmann, J., Hane, A., Burnson, C., Maleck, S., Hamburger, E., Shah, PE. Preterm infants who are prone to distress: Differential effects of parenting on 36-month behavioral and cognitive outcomes. Journal of Child Psychology and Psychiatry, and Allied Disciplines. 2012. http://dx.doi.org/ 10.1111/j.1469-7610.2012.02564.x

Poehlmann J, Schwichtenberg AJ, Bolt DM, Hane A, Burnson C, Winters J. Infant physiological regulation and maternal risks as predictors of dyadic interaction trajectories in families with a preterm infant. Developmental Psychology. 2011; 47(1):91-105. http://dx.doi.org/10.1037/ a0020719. [PubMed: 21244152]

Porges SW. Social engagement and attachment: A phylogenetic perspective. Annals of the New York Academy of Sciences. 2003a; 1008:31-47. [PubMed: 14998870]

Porges SW. The polyvagal theory: Phylogenetic contributions to social behavior. Physiology \& Behavior. 2003b; 79(3):503-513. [PubMed: 12954445]

Porges SW. The polyvagal theory: New insights into adaptive reactions of the autonomic nervous system. Cleveland Clinic Journal of Medicine. 2009; 76(Suppl 2):S86-S90. http://dx.doi.org/ 10.3949/ccjm.76.s2.17. [PubMed: 19376991]

Pratt M, Apter-Levi Y, Vakart A, Feldman M, Fishman R, Feldman T, ... Feldman R. Maternal depression and child oxytocin response: Moderation by maternal oxytocin and relational behavior. Depression and Anxiety. 2015; 32(9):635-646. http://dx.doi.org/10.1002/da.22392. [PubMed: 26130435]

Pridham K, Bhattacharya A, Thoyre S, Steward D, Bamberger J, Wells J, ... O’Brien M. Exploration of the contribution of biobehavioral variables to the energy expenditure of preterm infants. 
Biological Research for Nursing. 2005; 6(3):216-229. http://dx.doi.org/

10.1177/1099800404272310. [PubMed: 15583362]

Pridham KF, Brown R, Clark R, Sondel S, Green C. Infant and caregiving factors affecting weight-forage and motor development of full-term and premature infants at 1 year post-term. Research in Nursing \& Health. 2002; 25(5):394-410. http://dx.doi.org/10.1002/nur.10047. [PubMed: 12221693]

Putnam PT, Roman JM, Zimmerman PE, Gothard KM. Oxytocin enhances gaze-following responses to videos of natural social behavior in adult male rhesus monkeys. Psychoneuroendocrinology. 2016; 72:47-53. http://dx.doi.org/10.1016/j.psyneuen.2016.05.016. [PubMed: 27343726]

Rahkonen P, Heinonen K, Pesonen AK, Lano A, Autti T, Puosi R, ... Räikkönen K. Mother-child interaction is associated with neurocognitive outcome in extremely low gestational age children. Scandinavian Journal of Psychology. 2014; 55(4):311-318. http://dx.doi.org/10.1111/sjop.12133. [PubMed: 24828833]

Reynolds LC, Duncan MM, Smith GC, Mathur A, Neil J, Inder T, Pineda RG. Parental presence and holding in the neonatal intensive care unit and associations with early neurobehavior. Journal of Perinatology. 2013; 33(8):636-641. http://dx.doi.org/10.1038/jp.2013.4. [PubMed: 23412640]

Rubin LH, Carter CS, Drogos L, Pournajafi-Nazarloo H, Sweeney JA, Maki PM. Peripheral oxytocin is associated with reduced symptom severity in schizophrenia. Schizophrenia Research. 2010; 124(1-3):13-21. http://dx.doi.org/10.1016/j.schres.2010.09.014. [PubMed: 20947304]

Sansavini A, Zavagli V, Guarini A, Savini S, Alessandroni R, Faldella G. Dyadic co-regulation, affective intensity and infant's development at 12 months: A comparison among extremely preterm and full-term dyads. Infant Behavior \& Development. 2015; 40:29-40. http://dx.doi.org/10.1016/ j.infbeh.2015.03.005. [PubMed: 26021805]

Schore AN. Effects of a secure attachment on right brain development, affect regulation, and infant mental health. Infant Mental Health Journal. 2001; 22(1-2):7-66.

Seifer R, Sameroff AJ, Anagnostopolou R, Elias PK. Mother-infant interaction during the first year: Effects of situation, maternal mental illness, and demographic factors. Infant Behavior and Development. 1992; 15(4):405-426. http://dx.doi.org/10.1016/0163-6383(92)80010-R.

Ta BDP, Roze E, van Braeckel KNJA, Bos AF, Rassouli-Kirchmeier R, Hulscher JBF. Long-term neurodevelopmental impairment in neonates surgically treated for necrotizing enterocolitis: Enterostomy associated with a worse outcome. European Journal of Pediatric Surgery. 2011; 21(1):58-64. http://dx.doi.org/10.1055/s-0030-1267976. [PubMed: 21157690]

Thompson BL, Levitt P, Stanwood GD. Prenatal exposure to drugs: Effects on brain development and implications for policy and education. Nature Reviews. Neuroscience. 2009; 10(4):303-312. http:// dx.doi.org/10.1038/nrn2598. [PubMed: 19277053]

Thoyre SM, Brown RL. Factors contributing to preterm infant engagement during bottle-feeding. Nursing Research. 2004; 53(5):304-313. [PubMed: 15385867]

Thoyre SM, Carlson JR. Preterm infants' behavioural indicators of oxygen decline during bottle feeding. Journal of Advanced Nursing. 2003; 43(6):631-641. [PubMed: 12950569]

Thoyre, SM., Hubbard, C., Park, J., Pridham, K., McKechnie, A. Implementing coregulated feeding with mothers of preterm infants. MCN. The American Journal of Maternal Child Nursing. 2016. http://dx.doi.org/10.1097/NMC.0000000000000245

Thoyre SM, Shaker CS, Pridham KF. The early feeding skills assessment for preterm infants. Neonatal Network: NN. 2005; 24(3):7-16.

Ulmer-Yaniv A, Avitsur R, Kanat-Maymon Y, Schneiderman I, Zagoory-Sharon O, Feldman R. Affiliation, reward, and immune biomarkers coalesce to support social synchrony during periods of bond formation in humans. Brain, Behavior, and Immunity. 2016; 56:130-139. http://dx.doi.org/ 10.1016/j.bbi.2016.02.017.

Verbalis JG, Blackburn RE, Hoffman GE, Stricker EM. Establishing behavioral and physiological functions of central oxytocin: Insights from studies of oxytocin and ingestive behaviors. Advances in Experimental Medicine and Biology. 1995; 395:209-225. [PubMed: 8713970]

Verbalis JG, McCann MJ, McHale CM, Stricker EM. Oxytocin secretion in response to cholecystokinin and food: Differentiation of nausea from satiety. Science (New York, NY). 1986; 232(4756):1417-1419. 
Volpe JJ. Brain injury in premature infants: A complex amalgam of destructive and developmental disturbances. Lancet Neurology. 2009; 8(1):110-124. http://dx.doi.org/10.1016/ S1474-4422(08)70294-1. [PubMed: 19081519]

Weber AM, Harrison TM. Maternal behavior and infant physiology during feeding in premature and term infants over the first year of life. Research in Nursing \& Health. 2014; 37(6):478-489. http:// dx.doi.org/10.1002/nur.21618. [PubMed: 25223730]

Weber AM, Harrison TM, Steward DK. Schore's regulation theory: Maternal-infant interaction in the NICU as a mechanism for reducing the effects of allostatic load on neurodevelopment in premature infants. Biological Research for Nursing. 2012; 14(4):375-386. http://dx.doi.org/ 10.1177/1099800412453760. [PubMed: 22833586]

Weinstein M, Marom R, Berger I, Ben Bashat D, Gross-Tsur V, Ben-Sira L, ... Geva R. Neonatal neuropsychology: Emerging relations of neonatal sensory-motor responses to white matter integrity. Neuropsychologia. 2014; 62:209-219. http://dx.doi.org/10.1016/j.neuropsychologia. 2014.07.028. [PubMed: 25090927]

Weisman O, Zagoory-Sharon O, Feldman R. Oxytocin administration to parent enhances infant physiological and behavioral readiness for social engagement. Biological Psychiatry. 2012; 72(12): 982-989. http://dx.doi.org/10.1016/j.biopsych.2012.06.011. [PubMed: 22795645]

White-Traut R, Norr K. An ecological model for premature infant feeding. Journal of Obstetric, Gynecologic, and Neonatal Nursing: JOGNN/NAACOG. 2009; 38(4):478-489. http://dx.doi.org/ 10.1111/j.1552-6909.2009.01046.x.

Wolke D, Eryigit-Madzwamuse S, Gutbrod T. Very preterm/very low birthweight infants' attachment: Infant and maternal characteristics. Archives of Disease in Childhood. Fetal and Neonatal Edition. 2014; 99(1):F70-F75. http://dx.doi.org/10.1136/archdischild-2013-303788. [PubMed: 23792355] 


\section{Table 1}

Maternal-infant demographics.

\begin{tabular}{|c|c|c|c|c|}
\hline Maternal demographics & Mean & Std. Dev. & Min & $\operatorname{Max}$ \\
\hline Maternal age (years) & 30 & 8.05 & 18 & 43 \\
\hline Maternal education (years) & 14.56 & 2.58 & 11 & 20 \\
\hline Family income \$ (thousands) & 55 & 42.16 & 0 & 100 \\
\hline Births/Para & 1.73 & 1.31 & 1 & 7 \\
\hline Race & \multicolumn{4}{|c|}{$85 \%$ Caucasian } \\
\hline Marital status & \multicolumn{2}{|c|}{ Frequency } & & Percent \\
\hline Single, never married & \multicolumn{2}{|c|}{6} & & 20 \\
\hline Married & \multicolumn{2}{|c|}{17} & & 56.67 \\
\hline Partnered, not living together & \multicolumn{2}{|c|}{2} & & 6.67 \\
\hline Partnered, living together & \multicolumn{2}{|c|}{5} & & 16.67 \\
\hline Infant demographics $(N=28)$ & \multicolumn{2}{|l|}{ Mean } & Min & Max \\
\hline Gestational age at birth (weeks) & \multicolumn{2}{|l|}{27.25} & 25.57 & 28.86 \\
\hline Birthweight (g) & \multicolumn{2}{|l|}{1009.43} & 380 & 1470 \\
\hline APGAR at $5 \mathrm{~min}$ & \multicolumn{2}{|l|}{6.86} & 2 & 9 \\
\hline Neurobiological Risk Score & \multicolumn{2}{|l|}{3.32} & 0 & 11 \\
\hline Gender & \multicolumn{2}{|c|}{$50 \%$ male } & & \\
\hline Race & \multicolumn{2}{|c|}{$80 \%$ Caucasian } & & \\
\hline Multiples & \multicolumn{2}{|l|}{$10 \%$} & & \\
\hline
\end{tabular}

Infant Behav Dev. Author manuscript; available in PMC 2018 August 01. 


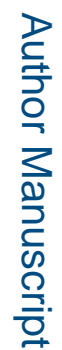

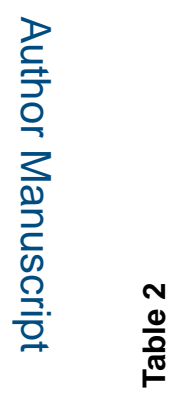

롤

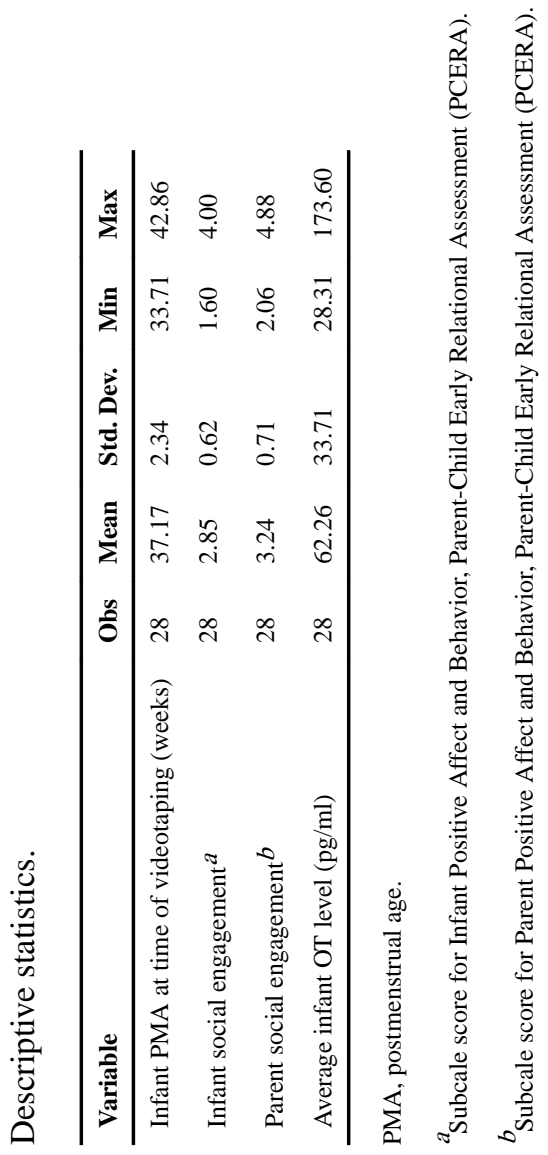

Infant Behav Dev. Author manuscript; available in PMC 2018 August 01. 
Table 3

Linear mixed model of infant social engagement and logged plasma oxytocin levels.

\begin{tabular}{lcccc}
\hline Log plasma (pg/ml) & Coef. & $\boldsymbol{p}>\mathbf{z}$ & [95\% conf. interval] & \\
\hline Infant social engagement & -0.32 & 0.01 & -0.57 & -0.07 \\
Gestational age at birth (weeks) & -0.05 & 0.57 & -0.23 & 0.13 \\
Birthweight & $<0.01$ & 0.94 & $<-0.01$ & $<0.01$ \\
Neurobiological Risk Score & -0.01 & 0.64 & -0.07 & 0.04 \\
Postmenstrual age (weeks) & -0.07 & 0.08 & -0.15 & 0.01 \\
Age at videotaping & -0.01 & 0.20 & -0.03 & 0.01 \\
\hline Random-effects parameters & Estimate & \multicolumn{2}{|c}{ [95\% conf. interval] } & \\
\hline Unstructured matrix & & & & \\
$\sigma_{b 0}$ (random intercepts) & 0.11 & & 0.01 & 2.09 \\
sd (Residual) & 0.60 & \multicolumn{5}{c}{0.50} & 0.71 \\
\hline
\end{tabular}


Table 4

Multiple linear regression of infant and maternal social engagement.

\begin{tabular}{lllll}
\hline Infant social engagement & Coef. & $\boldsymbol{p}>\boldsymbol{t}$ & [95\% conf. interval] & \\
\hline Maternal social engagement & 0.51 & 0.01 & 0.12 & 0.90 \\
Maternal age (years) & -0.02 & 0.24 & -0.06 & 0.02 \\
Maternal education (years) & 0.05 & 0.46 & -0.08 & 0.17 \\
Income (thousands \$) & -0.04 & 0.29 & -0.12 & 0.04 \\
Para & 0.20 & 0.08 & -0.03 & 0.43 \\
Marital status & 0.01 & 0.84 & -0.14 & 0.17 \\
\hline
\end{tabular}


Table 5

Multiple linear regression of maternal demographics and social engagement.

\begin{tabular}{lllll}
\hline Maternal social engagement & Coef. & $\boldsymbol{p}>\boldsymbol{t}$ & [95\% conf. interval] & \\
\hline Maternal age (years) & 0.02 & 0.40 & -0.03 & 0.06 \\
Maternal education (years) & -0.09 & 0.19 & -0.24 & 0.05 \\
Income (thousands \$) & 0.03 & 0.49 & -0.06 & 0.12 \\
Para & -0.29 & 0.02 & -0.52 & -0.05 \\
Marital status & -0.11 & 0.20 & -0.29 & 0.06 \\
\hline
\end{tabular}

